\title{
Laser intrastromal keratomileusis for high myopia and myopic astigmatism
}

\author{
P I Condon, M Mulhern, T Fulcher, A Foley-Nolan, M O'Keefe
}

\begin{abstract}
Background-Laser intrastromal keratomileusis (LASIK) is an evolving technique which enables high degrees of myopia (>8.0 dioptres) and myopic astigmatism to be corrected. This paper describes initial experience with this procedure. It also details the methodology, the results, the problems encountered, and discusses retreatment procedures.

Methods-51 eyes (48 primary cases and three retreatments) underwent LASIK for simple myopia or compound myopic astigmatism. After the keratotomy was fashioned with a Chiron corneal shaper, the ablation was performed with either a Summit or Meditec excimer laser. The actual preoperative astigmatism ranged from $-0.5 \mathrm{D}$ to $-6.0 \mathrm{D}$ (in the astigmatic myopic LASIK (AML) series), while the range of preoperative myopia in the combined myopic LASIK (ML) and AML series was $-8.0 \mathrm{D}$ to $-37.0 \mathrm{D}$. Of the $\mathrm{ML}$ cases, group 1 ( -8.0 to $-15.0 \mathrm{D}$ (dioptres)), group $2(>-15.0$ to $-20.0 \mathrm{D})$, and group 3 $(>-20.0$ D) had mean preoperative myopia values (spherical equivalent) of $-11.26 \mathrm{D},-16.84 \mathrm{D}$ and $-27.78 \mathrm{D}$. The same groupings $(1,2$, and 3$)$ for the AML

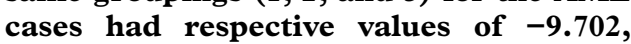
-17.4 , and -23.08 . In the AML series the mean preoperative astigmatism was -2.109 D. Follow up ranged from 8 to 27 months (mean 15.8 months). Six of the cases required retreatment.
\end{abstract}

Results-There was a reduction in best corrected visual acuity (BCVA) (of 1 Snellen line) in seven of the primary cases $(14.5 \%)$ (three in the ML group and four in the AML group), and in one of the retreatment cases. The BCVA improved in 28 cases $(58 \%)$ in the primary treatment group. The mean correction attempted (spherical equivalent) for the ML groups 1,2 , and 3 was $10.51 \mathrm{D},-14.5 \mathrm{D}$, and -27.78 $D$, versus a mean correction achieved of -9.445 D, -15.625 D, and -21.571 D. Similarly, for the AML groups, attempted correction values were $-9.702 \mathrm{D},-17.4 \mathrm{D}$, and $-23.08 \mathrm{D}$, while the values achieved were $-6.95 \mathrm{D},-51.425 \mathrm{D}$, and $-15.708 \mathrm{D}$. Regression was minimal and stabilisation of the refractive result was achieved in all groups, except group 3 of the ML series, by the 3 month examination period. The mean postoperative astigmatism in the AML series was $-0.531 \mathrm{D}$. Vector analysis of the AML series showed that the mean surgically induced astigmatism was +0.93 D. The most common complication encountered was undercorrection, which occurred in 35 cases-23 cases in the ML group and 12 cases in the AML series. Twenty eight per cent of the ML cases, and $25 \%$ of the AML cases were within plus or minus $1.5 \mathrm{D}$ of the attempted refraction. Conclusion-For the correction of high myopia and myopic astigmatism, LASIK results in less postoperative pain and relatively little subepithelial haze compared with high myopic photorefractive keratectomy. Furthermore, a stable refraction and reasonably predictable outcome occurs much earlier. High myopia up to $-37.0 \mathrm{D}$ can be corrected, albeit with some limitations at the extremes of myopia-in terms of the amount of myopia correctable; this represents a limitation of the technique. Retreatment is a technically straightforward and effective way to treat undercorrection. Undercorrection, the main complication seen in our series, should become less common when the ablation algorithms are further refined. (Br F Ophthalmol 1997;81:199-206)

When compared with the lower degrees of myopia, the correction of high myopia by photorefractive keratectomy (PRK) has been shown to produce a greater amount of corneal haze and regression..$^{1-7}$ Attempts are being made to expand the range of myopia which can be corrected by PRK using multizone/ multipass techniques, but to date, experience with these techniques is limited to the short term only. ${ }^{8}$ Following Buratto's initial concept of intrastromal ablation of an excised corneal cap, with replacement of the cap and retention of Bowman's membrane, and the possibility of intrastromal treatment in situ, Pallikaris et al introduced the concept of hinging the corneal cap, in order to minimise displacement and subsequent irregular astigmatism. ${ }^{910}$ By respecting Bowman's membrane, it is generally felt that corneal haze and postoperative regression can be minimised. ${ }^{11}$ In the current literature several reports, ${ }^{12-22}$ discuss this new technique, but only on ${ }^{19}$ describes the use of laser intrastromal keratomileusis (LASIK) to correct compound myopic astigmatism-that is, astigmatic myopic LASIK (AML). We discuss the results of treatment for simple myopia and compound myopic astigmatism, in a series with a mean follow up of 15.8 (SD 4.53) months, and in particular, the critical 
criteria for treating extreme myopia (in the range -20.0 to $-40.0 \mathrm{D}$ ).

\section{Patients and methods}

Patients with myopia greater than $8.0 \mathrm{D}$ were considered as potential candidates for LASIK. Exclusion criteria were evidence of corneal warpage from prolonged recent contact lens wear, tear film abnormality, corneal dystrophy, keratoconus, unstable myopia, patients with early cataracts, and eyes with pachymetry values less than $450 \mu \mathrm{m}$, diabetes mellitus, or collagen vascular disease. All patients were informed about the procedure, its risks, advantages, and disadvantages before surgery.

The preoperative examination consisted of a complete anterior and posterior segment examination, retinoscopy, videokeratography, and an endothelial cell count.

A cohort of 60 cases was assembled from a review of the hospital notes. Five cases were excluded from this study because of age (less than 18 years old). Three further cases were excluded from the study because the patients had previous corneal surgery (repair of a corneal perforation, failed Draeger's and Schneider's procedures - one case each). The remaining 52 cases included nine patients with amblyopia (either due to refractive and/or strabismic origin), and four patients who were retreated, together with one patient who was due to be retreated but the procedure was cancelled as the cornea was too thin to allow retreatment (see Table 1). The results from this latter group will not be included in the main body of the results. Cases were primarily classed as myopic LASIK (ML) 32 cases; AML 16; or retreatment three; and one cancellation. They were then further subclassed as group 1 $(-8$ to $-15 \mathrm{D})$, group $2(>-15.0 \mathrm{D}$ to -20.0 $\mathrm{D})$, or group $3(>-20.0 \mathrm{D})$, depending on their preoperative refraction (spherical equivalent). Of the ML class the composition was as follows: group $1(n=16)$, group $2(n=8)$, and group $3(n=8)$, while for the AML class group $1(n=8)$, group $2(n=5)$, and group $3(n=3)$. The age range was $18-56$ years, the means (SD) for the ML groups were: 37.25 (10.45) years group $1 ; 30.625$ (11.31) years group 2; and 34 (9.865) years group 3. For the AML series the values were: 33.125 (4.12) years group $1 ; 32.2$ (9.066) years group 2 ; and 41.33 (11.59) years group 3.

Seventy per cent of the cases were female. Eight of the ML cases (25\%) were treated using the Summit laser and the remainder with the Meditec laser. All the AML and retreatment groups were treated using the Meditec laser. The preoperative myopia for the modified cohort ranged from -8.0 to $-37.0 \mathrm{D}$. In the ML groups, the mean (SD) preoperative refractions were as follows: group $1-11.26$ (2.564)D; group $2-16.84(0.825) \mathrm{D}$; and group $3-27.781$ (5.544) D. In the AML groups the preoperative refractions were group $1-9.702(1.786) \mathrm{D}$; group $2-17.4(2.553) \mathrm{D}$; and group $3-23.083$ (5.257) D. Six cases in our series had LASIK for myopia greater than $-20.0 \mathrm{D}$ (see Table 2). The range of preopera- tive astigmatism was from -0.5 to $-6.0 \mathrm{D}$. The mean preoperative astigmatism -2.35 (1.52) D.

Four cases were reoperated by lifting up the previously created corneal flap and retreating in the previously ablated area (see Table 1). A further case is currently scheduled for retreatment for an undercorrection. In one $-25.0 \mathrm{D}$ eye (case 5), a decision to re-treat was cancelled because of an excessively thin residual cornea (of $120 \mu \mathrm{m}$ ) in the previously ablated area.

Whereas the majority of LASIK procedures were carried out under topical anaesthesia, a total of seven patients opted to have general anaesthesia. Topical anaesthesia consisted of $1.0 \%$ amethocaine, one drop every 3 minutes for the first 15 minutes, which was then followed by a mixture of $0.5 \mathrm{ml} \quad 4.0 \%$ Xylocaine (lignocaine) and $0.5 \mathrm{ml}$ of $0.75 \%$ Marcaine (bupivacaine) with adrenaline, one drop per minute for 7 minutes. The eyes were draped using lint-free plastic sheeting: Steristrips and a Nevyas speculum combined to give maximum exposure of the cornea and perilimbal sclera. Intraoperative pachymetry was performed using a Corneogage pachymeter (Sonogage).

Following patient fixation on the red $\mathrm{HeNe}$ laser beam, a Ruiz optical zone marking device dipped in gentian violet was used to make a pararadial 12 o'clock mark on the cornea (patients' pupils were not constricted preoperatively with pilocarpine). This was followed by application of the $9 \mathrm{~mm}$ LASIK suction ring to the limbus; the increase in intraocular pressure is verified with a Barraquer applanation tonometer on a dried corneal surface; just before the microkeratome (with preset hinge stop) is placed on the ring track. The microkeratome was then activated to pass across the cornea, and then reversed before releasing the vacuum. The flap was then reflected, and pachymetry used to measure the residual stroma and to verify the thickness of the corneal flap. Care was taken to prevent moisture from tears, or contaminants from the lids from impinging on the exposed stromal surface. Ablation of the underlying stroma was then carried out using the excimer laser.

The Summit Technology laser used in our series was an ExciMed UV200LA argon fluoride laser, which produced pulsed laser radiation at a wavelength of $193 \mathrm{~nm}$, and with a fluence of $180 \mathrm{~mJ} / \mathrm{cm}^{2}$ at the stromal surface. The Aesculap device was a Meditec Excimer laser (MEL 60), also producing laser radiation of wavelength $193 \mathrm{~nm}$, but with a fluence of $200 \mathrm{~mJ} / \mathrm{cm}^{2}$ at the stromal surface. The algorithm for the Summit laser utilised the inbuilt MKM software program, the spherical equivalent corrected for back vertex distance being entered into the computer. In cases of astigmatism greater than $3.0 \mathrm{D}, 70 \%$ instead of the usual $50 \%$ of minus cylinder was added to the spherical component. With the Meditec laser, where correction of astigmatism was possible, the policy was to fully correct all minus cylinder greater than $-0.5 \mathrm{D}$. The ablation was 
Table 1 Details of the cases requiring retreatment

\begin{tabular}{|c|c|c|c|c|c|c|}
\hline Case & $\begin{array}{l}\text { Preoperative } \\
\text { refraction }\end{array}$ & $\begin{array}{l}\text { Postoperative } \\
\text { refraction }\end{array}$ & Ablation & $\begin{array}{l}\text { Correction } \\
\text { attempted }\end{array}$ & $\begin{array}{l}\text { Correction } \\
\text { achieved }\end{array}$ & Comment \\
\hline \multirow[t]{2}{*}{1} & $-28.5 \mathrm{D}$ & $-9.0 \mathrm{D}$ & $-19.0 \mathrm{D}$ & $-28.0 \mathrm{D}$ & $-19.0 \mathrm{D}$ & Undercorrected \\
\hline & $-9.0 \mathrm{D}$ & $-1.0 \mathrm{D}$ & $-9.0 \mathrm{D}$ & $-9.0 \mathrm{D}$ & $-8.0 \mathrm{D}$ & Retreatment \\
\hline \multirow[t]{2}{*}{2} & $-7.0 \mathrm{D}$ & $-4.5 \mathrm{D}$ & $-6.5 \mathrm{D}$ & $-6.5 \mathrm{D}$ & $-4.5 \mathrm{D}$ & Undercorrected \\
\hline & $-4.5 \mathrm{D}$ & $-0.75 \mathrm{D}$ & $-4.5 \mathrm{D}$ & $-4.5 \mathrm{D}$ & $-3.75 \mathrm{D}$ & Retreatment \\
\hline 3 & $\begin{array}{l}-15.0 /-2.0 \times 15 \\
-7.0 /-1.0 \times 10\end{array}$ & $\begin{array}{l}-7.0 /-1.0 \times 10 \\
-1.0 \mathrm{D}\end{array}$ & $\begin{array}{l}-13 /-2 \\
-7.0 /-1.0\end{array}$ & $\begin{array}{l}-13 /-2 \\
-7.0 /-1.0\end{array}$ & $\begin{array}{l}-6.5 \mathrm{D} \\
-6.5 \mathrm{D}\end{array}$ & $\begin{array}{l}\text { Epithelial ingrowth and undercorrected } \\
\text { Retreatment and removal of epithelial } \\
\text { ingrowth }\end{array}$ \\
\hline 4 & $-25.0 \mathrm{D}$ & $-9.0 \mathrm{D}$ & $-19.0 \mathrm{D}$ & $-19.0 \mathrm{D}$ & $-17.0 \mathrm{D}$ & Central island \\
\hline & $-9.0 \mathrm{D}$ & $-2.0 \mathrm{D}$ & $-7.5 \mathrm{D}$ & $-7.5 \mathrm{D}$ & $-7.0 \mathrm{D}$ & Retreatment \\
\hline 5 & $-25.0 \mathrm{D}$ & $-6.0 \mathrm{D}$ & $-21.0 \mathrm{D}$ & $-25.0 \mathrm{D}$ & $-19.0 \mathrm{D}$ & $\begin{array}{l}\text { Undercorrected residual cornea too thin to } \\
\text { retreat }\end{array}$ \\
\hline 6 & $-10.0 \mathrm{D}$ & $-3.25 \mathrm{D}$ & $-10.0 \mathrm{D}$ & $-10.0 \mathrm{D}$ & $-6.75 \mathrm{D}$ & Undercorrected. Scheduled for retreatment \\
\hline
\end{tabular}

performed at a single optical zone- $-5.0 \mathrm{~mm}$ for the Summit laser and $5.5 \mathrm{~mm}$ for the Meditec laser.

After laser ablation, the flap was washed thoroughly with balanced salt solution (BSS) by irrigation directly through a lacrimal cannula, while simultaneously aspirating the excess fluid and conjunctival secretions with a standard suction handpiece, which was placed close to the flap in the conjunctival fornix. The flap was then rotated into its normal anatomical position overlying the stromal bed using a fine gauge Rycroft cannula attached to a syringe, which lifted the flap from the epithelial side, the stroma being kept totally dry and free from particulate matter throughout the manoeuvre. Centration was checked by gross inspection, utilising the landmarks provided earlier by the optical zone marker. After several minutes, cap bed adherence was checked by depressing the peripheral cornea adjoining the edge of the flap and watching for an associated dimpling effect of the flap, which became evident when adherence was good. The speculum and drapes were then carefully removed, and the integrity of cap adherence checked under the microscope by asking the patient to blink. Two drops of Betadine (diluted 50\%) and gentamicin were then instilled into the conjunctival fornix; then a Cartella shield was placed over the eye. Topical gentamicin was subsequently used over the next 3 to 4 days postoperatively.

Patients were reviewed on the first and fourth postoperative days, and subsequently at 1, 3, 6 weeks, 3 months, 6 months, and 1 year, and as required thereafter. Postoperative videokeratography was performed at the 3 week and 6 month stages. Non-contact specular microscopy was performed at the 6 month stage. At each examination interval, unaided and best corrected visual acuity (BCVA) were determined, and the cornea was examined at the slit-lamp to detect microstriae, interface haze and debris, the centration of the ablation, and to verify the position of the cap on its corneal bed.

Retreatment was indicated in this series if (i) the sphere was undercorrected by $-3.0 \mathrm{D}$ or more, (ii) a central island was evident on topography, (iii) the patient was at least 9 months post treatment. For retreatment procedures (Table 1), following careful removal of the epithelium around the edge of the corneal flap using a Beaver 66 blade or a hockey knife blade, the edge of the flap is lifted gently using the fine blade edge, until an adequate amount of tissue is reflected, which will subsequently allow peeling backwards of the whole flap using a microforceps to grasp the edge without producing any damage to it. Pachymetry is immediately carried out to assess the residual stromal thickness, taking care to maintain complete dryness of the bed. Contraindication or limitation to the amount of repeated ablation depends on the amount of residual stroma. In this series, approximately $30 \%$ of the total corneal thickness was left intact beneath the ablated area in order to offset any subsequent danger of ectasia occurring. The corneal flap was then hydrated and replaced as in the primary procedure.

\section{Results}

BCVA deteriorated by 1 Snellen line in seven $(14.5 \%)$ of the primary cases, three of these were in the ML group, and four were in the AML group. One of the retreatment cases also had a reduction in BCVA by 1 Snellen line. The BCVA increased in $28(58 \%)$ cases postoperatively. Of the ML group $18(56 \%)$ had a one line gain in Snellen acuity, two $(6 \%)$ had a gain of 2 Snellen lines, and a further two $(6 \%)$ had a gain of 3 Snellen lines. The AML showed less benefit in terms of improved BCVA - five (31\%) gaining 1 line, and one case $(6 \%)$ gaining 3 lines. Two of the seven amblyopes who made up part of the ML series showed a gain in BCVA. Of the two amblyopes who were part of the AML series, only one showed a gain in BCVA. Group 3 (>-20.0 D) of the ML series had the highest percentage of cases (88\%) with improved BCVA. Groups 2 and 3 (equally) had the highest incidence of decreased BCVA (12\%). In the AML series also, group 3 had the highest percentage of cases showing increased BCVA-66\%; while group 2 had the highest percentage of cases with a decrease in BCVA- $40 \%$.

The effect of ML and AML on refraction is dealt with below (see Table 2). The main information from this table is that ML would seem to be much more predictable than AML for any degree of myopia (groups 1,2, or 3). The mean values for the correction attempted versus the correction achieved, and the values for the percentage correction attempted versus achieved seem respectable for both the ML and AML series, but examination of the percentage of cases obtaining within $1.5 \mathrm{D}$ or $-2.5 \mathrm{D}$ of the attempted correction may be more informative and realistic. 
Table 2 Refractive variables for this series

\begin{tabular}{|c|c|c|c|c|c|c|c|}
\hline \multirow[b]{2}{*}{ Group } & \multicolumn{2}{|c|}{ Refraction (mean (SD)) } & \multicolumn{2}{|c|}{ Correction (mean (SD)) } & \multirow{2}{*}{$\begin{array}{l}\% \text { of correction } \\
\text { attempted }\end{array}$} & \multicolumn{2}{|c|}{$\%$ within $-1.5 \mathrm{D}$ or $-2.5 \mathrm{I}$} \\
\hline & Preop & Postop & Attempted & Achieved & & $-1.5 \mathrm{D}$ & $-2.5 \mathrm{D}$ \\
\hline \multicolumn{8}{|c|}{ Myopic LASIK series: } \\
\hline 1 & $-11.26(2.564)$ & $-1.74(2.285)$ & $-10.51(2.224)$ & $-9.445(3.67)$ & 90 & 37 & 25 \\
\hline 2 & $-16.84(0.825)$ & $-0.843(3.285)$ & $-14.5(1.309)$ & $-15.625(3.67)$ & 108 & 37 & 37 \\
\hline 3 & $-27.78(5.544)$ & $-4.781(5.957)$ & $-21(4.123)$ & $-21.571(4.032)$ & 102 & 0 & 25 \\
\hline \multicolumn{8}{|c|}{ Astigmatic myopic LASIK series: } \\
\hline 1 & $-9.702(1.786)$ & $-2.75(3.638)$ & $-9.671(1.792)$ & $-6.952(3.165)$ & 72 & 12 & 50 \\
\hline 2 & $-17.4(2.553)$ & $-1.925(1.35)$ & $-17.1(2.625)$ & $-15.42(3.53)$ & 90 & 40 & 20 \\
\hline 3 & $-23.083(5.257)$ & $-7.078(2.194)$ & $-19.583(2.919)$ & $-15.708(4.66)$ & 80 & 33 & 0 \\
\hline
\end{tabular}

Table 3 LASIK for the extremes of myopia ( -20.0 to $-40.0 \mathrm{D})$

\begin{tabular}{llllll}
\hline & \multicolumn{5}{l}{ Corneal thickness $(\mu \mathrm{m})$} \\
\cline { 3 - 6 } $\begin{array}{l}\text { Preoperative } \\
\text { refraction }\end{array}$ & $\begin{array}{l}\text { Postoperative } \\
\text { refraction }\end{array}$ & Preoperative & Flap & Residual & $\begin{array}{l}\text { (\% of original } \\
\text { thickness) }\end{array}$ \\
\hline$-22.0 \mathrm{D}$ & $-4.0 /+3.0 \times$ & 550 & 186 & 164 & $(29.8 \%)$ \\
$-23.0 \mathrm{D}$ & 180 & & & & \\
$-24.0 \mathrm{D}$ & $-1.0 \mathrm{D}$ & 500 & 108 & 186 & $(37 \%)$ \\
$-26.0 /+6.0 \times 30$ & $-5.0 /+6.0 \times 30$ & 550 & 110 & 273 & $(49 \%)$ \\
$-30.0 \mathrm{D}$ & $-8.0 /+1.0 \times 40$ & 540 & 135 & 230 & $(42 \%)$ \\
$-37.0 \mathrm{D}$ & -3.0 & 580 & 120 & 230 & $(39.6 \%)$ \\
\hline
\end{tabular}

All cases were deliberately undercorrected.

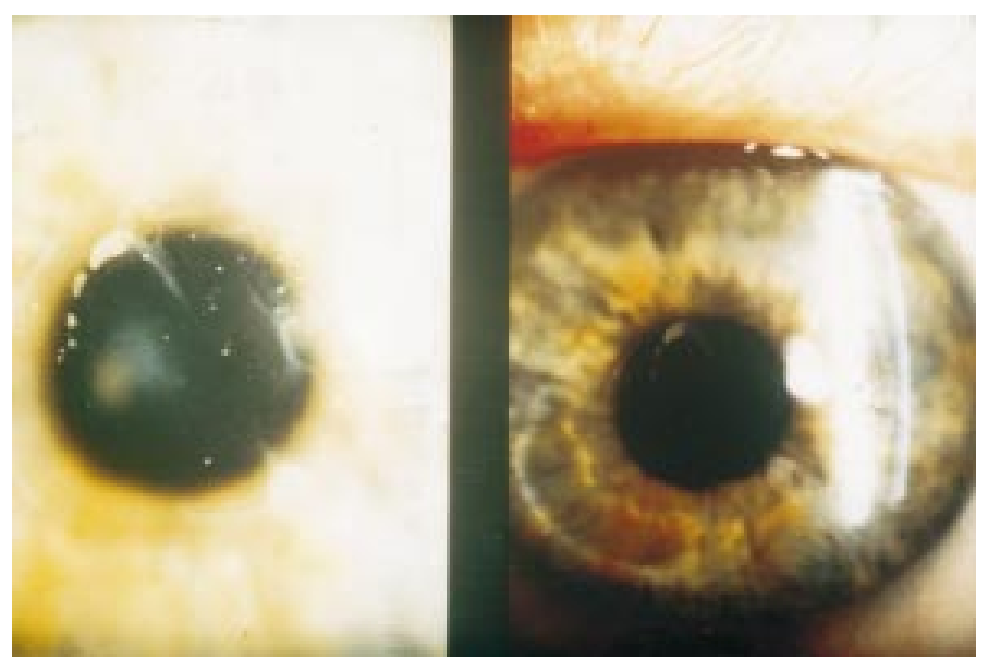

Figure 1 Epithelial ingrowth occurring after LASIK.

Six eyes in our series had preoperative myopia of between -20.0 and $-40.0 \mathrm{D}$. The maximal correction in these eyes was limited to the extent that $30 \%$ of the preoperative corneal thickness was left undisturbed beneath the ablated area in order to avoid a possible subsequent ectasia of the cornea. In these cases full correction was not possible and a deliberate undercorrection was achieved. Table 3 lists the pre- and postoperative characteristics of these cases. Astigmatism and myopia (compound myopic astigmatism) were corrected in 16 cases (that is, the AML group). The magnitude of the preoperative cylinder corrected (that is, attempted) was -0.5 to $-6.0 \mathrm{D}$, with a mean of -2.109 (SD 1.855) D. Postoperatively, the cylindrical component range was reduced to between $0.0 \mathrm{D}$ and $-3.25 \mathrm{D}$, with a mean value of -0.531 (1.83) D. The correction achieved was -1.71 (2.39) D, giving a predictability (when expressed as a percentage of correction attempted) of $81 \%$. Vector analysis using the Naylor method, ${ }^{23}$ showed that the mean surgically induced refractive cylinder (of the AML series) was +0.93 (2.30) $\mathrm{D}$, range 0 to $5.0 \mathrm{D}$.

Regression of the correction is a major obstacle to the final success of high myopic PRK. ${ }^{1-5} 7$ In this series of LASIK cases, we examined the refraction to ascertain the effect of regression at 1 month, 1-3 months, 3-6 months, and 1 year (Table 4 ).

A significant decentration of the ablation was seen in eight cases: seven of these (all in the ML groups) were performed using a Summit laser, but only one case (part of the AML group) was associated with the use of the Aesculap Meditec laser. Ablation decentration ranged from $0.5-1.60 \mathrm{~mm}$, with a mean value of $1.20 \mathrm{~mm}$ and in four of these cases the ecentration induced a degree of astigmatism.

Corneal complications occurred in 17 cases (see Table 5). Epithelial cell nests occurred in three patients but were not treated (see Fig 1). Active epithelial ingrowth appearing on slitlamp examination as a focal cystic lesion originating from the extreme periphery of the flapstromal bed interface, and actively progressing across the cornea, under the flap, occurred in two cases. This was accompanied by the development of increasing irregular asymmetric astigmatism, decreasing BCVA. In both cases, relifting of the flap and removal of the cells was required; this immediately resulted in restoration of the central ablation zone topography, and recovery of BCVA.

Interface haze was graded as 0 to 2 . Nine patients demonstrated this complication, eight patients had grade 1 haze which was not associated with any subjective visual disability. One patient with grade 2 haze had severe difficulty driving at night. Despite meticulous

Table 4 Refraction (SD) at various postoperative intervals

\begin{tabular}{llllll}
\hline Group & 1st Postop day & 1 Month & 3 Months & 6 Months & 12 Months \\
\hline Myopic LASIK series: & & & & \\
1 & $-0.859(2.473)$ & $-1.138(2.09)$ & $-1.86(2.266)$ & $-1.861(2.675)$ & $-1.93(2.064)$ \\
2 & $-0.833(3.055)$ & $-2.25(0.353)$ & $-2.56(3.163)$ & $-2.687(3.977)$ & $-2.697(2.12)$ \\
3 & $-4.1(7.162)$ & $-4.291(3.241)$ & $-4.25(6.717)$ & $-6.166(5.636)$ & $-6.241(3.729)$ \\
Astigmatic myopic LASIK series: & & & & $-1.85(1.666)$ \\
1 & $0(1.732)$ & $-1.25(0.787)$ & $-1.75(1.433)$ & $-1.75(1.658)$ & $-1.999(2.222)$ \\
2 & $-1.0416(2.796)$ & $-1.25(2.327)$ & $-1.975(2.242)$ & $-1.989(2.242)$ & $-4.2(3.907)$ \\
3 & $-3.14(5.142)$ & $-3.673(4.131)$ & $-4.0(4.1)$ & $-4.114(4.179)$ & \\
\hline
\end{tabular}


Table 5 Complications of LASIK

Undercorrection greater than $-1.5 \mathrm{D}$

Retreatment required *

Corneal haze

Decentred ablation

Epithelial ingrowth

Interface debris

Cap stress lines

35 cases

6 cases

9 cases

8 cases

3 cases

3 case

2 cases

*One retreatment is scheduled, and one case could not be retreated as the residual cornea was too thin.

intraoperative care to avoid contamination of the flap-bed interface, particulate debris, possibly derived from defective cellulose sponges, or from the microkeratome blade, was seen in three cases. No case of interface debris was associated with any inflammatory reaction. The incidence of other corneal complications is given in Table 5. At the level of the epithelium, an incomplete circular corneal ring, brown in colour, is often seen in the area flattened by the ablation, this is probably due to corneal tear pooling and iron deposition. Finally, specular microscopy which was performed preoperatively, and at 6 months postoperatively, demonstrated no significant reduction in endothelial cell count.

The incidence of subjective visual problems manifesting as glare (starbursting), monocular diplopia, or halo phenomenon was examined in this series. Severe glare was present in two cases (both members of ML group 1), preventing one patient from driving at night. Monocular diplopia was experienced by one patient in this series, who had an ablation decentration of $1.60 \mathrm{~mm}$. Halo phenomena were not noted in any patient after LASIK.

Apart from the four cases of astigmatism resulting from decentred ablations (all in ML groups), five eyes had astigmatism induced (range $0.75 \mathrm{D}$ to $1.75 \mathrm{D}$ ) by the treatment which was not associated with decentration. This was probably due to changes in the beam homogenicity of the laser head and will be discussed in a separate report.

\section{Discussion}

Currently, four procedures are in widespread use for the correction of myopia-radial keratotomy, clear lens exchange, PRK, and LASIK. For the correction of the lower degrees of myopia (up to $-6.0 \mathrm{D}$ ) PRK gives a predictable outcome. However, for higher degrees of myopia (greater than -8.0 D) PRK is associated with an unacceptable degree of regression and subepithelial haze. ${ }^{1-7}$ To overcome these drawbacks, new techniques for delivering the ablation in high myopia are being investigated-for example, multizone/ multipass procedures, and one recent study with a short term follow up ${ }^{8}$ suggests that it may be possible to expand the range of myopia correctable by PRK, thus overcoming the previous problems of regression and subepithelial haze. LASIK is evolving as the procedure of choice for the correction of myopia greater than $8.0 \mathrm{D}$. Intrastromal laser ablation utilising a corneal flap technique was shown to be possible by Pallikaris et al. ${ }^{10}$ There are several variations of the technique to create the LASIK flap-manual dissection ${ }^{15}$ of the flap, use of a Draeger keratome, ${ }^{12}$ or use of a Chiron microkeratome, as we describe. The ablation may be to the underside of the cap, the so called Buratto technique, ${ }^{24}$ now abandoned by its creator owing to the possibility of traumatising Bowman's membrane, ${ }^{17}{ }^{18}$ or to the stromal bed as described by Pallikaris et al. The reason for creating a flap, and for ablating the stromal bed rather than the cap, is that preservation of Bowman's membrane has been shown to be associated with a reduction in the amount of regression and haze induced. ${ }^{11}$

The potential disadvantages for high myopes treated by PRK include corneal haze, ${ }^{2-5}$ and a variable but significant amount of regression..$^{1-6}$ Nine patients in our LASIK series demonstrated interface haze, but this was only subjectively visually debilitating in one case. Of course, contrast sensitivity testing would perhaps uncover others who are asymptomatic, but to date, contrast sensitivity has not been examined in LASIK patients. Regression associated with high myopic PRK may be somewhat ameliorated by utilising a multizone technique $^{813}$ or tapered transition zones, ${ }^{425}$ but further research in these areas is warranted. Regression after LASIK is not a significant problem-we found that while the mean regression peaked at the 1-3 month period for all groups except group 3 of the ML series, the amount is insignificant, especially for this latter group, if one considers the range of myopia corrected. Compare this with the findings of Epstein $e t a l,{ }^{26}$ who showed that stabilisation of refraction does not occur until 18-24 months after PRK (for myopia up to $-7.5 \mathrm{D}$ ). The refraction in the postoperative period extending from 12 months on (up to a maximum of 27 months) continued to be stable, but the number of patients having such extensive follow up was not deemed sufficient to include them in Table 4.

Pallikaris and Siganos ${ }^{12}$ in their study of patients up to 1 year postoperatively, found a mean regression of less than $-1.50 \mathrm{D}$, with refraction tending to be stable after 1 month. The PRK group of Pallikaris and Siganos, ${ }^{12}$ however, showed extreme regression over a 1 year period, from $+1.29 \mathrm{D}$ (at 1 month postoperatively) to $-7.42 \mathrm{D}$ (at 12 months postoperatively). This large amount of regression associated with high myopic PRK is mirrored by other series in the literature. ${ }^{2-5}$

Of the 48 cases in our modified series, seven $(14 \%)$ showed a drop in visual acuity postoperatively of one Snellen line. In Pallikaris and colleagues' recent report, ${ }^{10}$ they described two cases $(20 \%)$ of reduced visual acuity which were due to interface abnormalities. We attribute six cases (of reduced visual acuity) to the same abnormality, as no obvious problems were detected on slit-lamp examination or videokeratography. The other case associated with a drop in visual acuity was in a patient with a central island-later successfully retreated (with a restoration of BCVA). One further case was associated with a retreatment procedure, which, of course, increases the risk of having interface abnormalities. In our series, 
28 cases (58\%) improved on their BCVA level. This contrasts with high myopic PRK, which is well documented as being associated with an appreciable loss of best preoperative acuity $-9 \%$ and $26 \%$ of cases showing reduced acuity levels in Heitzman and colleagues ${ }^{5}$ and Carson and Taylor's ${ }^{27}$ respective series. Our relatively high incidence of reduced BCVA (14\%) may be attributable to the learning curve associated with this technique, in particular the high degree of skill required to fashion the corneal flap with the microkeratome.

There are several studies which document the outcome of toric ablations using PRK, ${ }^{82-34}$ but there is only one published report concerning the effectiveness of astigmatic myopic LASIK (AML) as a means to correct compound myopic astigmatism. ${ }^{19}$ This study, however, reported the outcome of AML in only three eyes. In our series $(n=16)$, AML reduced the preoperative mean cylinder of -2.35 (1.52) $\mathrm{D}$ to a postoperative mean value of -0.531 (1.83) D. Although AML reduced the mean astigmatism, within a useful range (up to -6.0 D), many cases had some residual astigmatism, which could be due to errors in marking or ablating the cylindric axis or to decentration, this latter problem being a potential source of induced astigmatism. Unlike PRK, or photoastigmatic refractive keratectomy (PARK), astigmatism after LASIK or AML, while not being attributable to epithelial remodelling, can be due to interface irregularities. Vector analysis showed the surgically induced astigmatism to be 0.93 (2.301) $\mathrm{D}$ in the AML series, with a range of 0 to $5.0 \mathrm{D}$.

Our series has demonstrated that LASIK is very useful for the correction of very high (or 'extreme') myopia-see Table 3. Several factors determine the maximum correction possible for these individuals, (i) the total corneal thickness, (ii) the fact that a flap of not less than $120 \mu \mathrm{m}$ thickness must be created, (iii) the residual corneal thickness beneath the ablation must be not less than $30 \%$ of the original corneal thickness, and (iv) the diameter of the optical ablation zone (this in turn being related to the ablation depth). Often the full correction is not possible-and this represents a limitation of the technique, owing to some of the restrictions imposed by the above factors, and indeed all the cases in Table 3 were deliberately undercorrected. However, as new lasing strategies are developed-for example, multizone, more dioptric effect may become available from a shallower excavation. Only two of these six cases demonstrated interface haze (grade 1), regression did not amount to more than $4.00 \mathrm{D}$ in any of these cases; this latter result concurs with the findings of Gomes. ${ }^{15}$ The findings of Pop and Aras, ${ }^{8}$ as regards the efficacy of multizone/multipass PRK for the correction of high myopia and compound myopic astigmatism are hopeful $-78.4 \%$ of high myopes being within $2.0 \mathrm{D}$ of the intended correction at 6 months. They cannot, however, be directly compared with our results as multipass/multizone technology was not available when these cases were undertaken.
The major complications seen with the current LASIK technique are undercorrection and decentration. Undercorrection (greater than $-1.5 \mathrm{D}$ ) was the most frequent complication seen in our series, and 35 cases were undercorrected in total. This is a serious problem, but it is a problem attributable to the laser's inbuilt ablation algorithm rather than the procedure (LASIK) itself. In our series undercorrection was more than twice as common with the Meditec laser as with the Summit laser. Five patients required retreatment procedures to reduce undercorrection. Other centres have found predictability values (that is, the percentage of cases obtaining1.0 D of the attempted correction) of $66 \%$ (Pallikaris et $a l$ ) to $74 \%$ (Kremer et al); compared with our findings of $28 \%$ of the ML group, and $25 \%$ of the AML group being within $1.5 \mathrm{D}$ of the attempted correction. Our results may have been adversely influenced by the fact that two different lasers were used. This prevented us from developing long term experience with one device, which in turn would have allowed us to overcompensate for the laser's undercorrection. Fiander and Tayfour ${ }^{14}$ experienced a tendency towards overcorrection in their series. Our incidence of overcorrection was $20 \%$ for the combined ML and AML series. Overcorrection was less common in the AML series as the Meditec laser was tending to undercorrect, in comparison with the Summit laser-the AML series were all treated with the Meditec.

In our series eight cases demonstrated 'significant' decentration of the ablation zone. We defined 'significant' decentration as ablation decentration of $0.5 \mathrm{~mm}$ or more from the centre of the entrance pupil; the work of Cavanagh et al ${ }^{35}$ suggests that (for PRK) only decentration greater than $0.5 \mathrm{~mm}$ may be clinically significant. Of these cases, only one patient had postoperative monocular diplopia-so, subjectively, decentration seems to be well tolerated by LASIK patients. Our centre has compared the centration in myopic PRK and myopic LASIK groups ${ }^{36}$; we found centration to be worse in the LASIK groupthe magnitude of the displacement being almost twice as high in the LASIK group. This we attribute to three factors. Firstly, the majority of cases $(87 \%)$ in which decentration occurred were performed with the Summit laser, which depends very much on patient cooperation for optimal centration. The Meditec laser was associated with more accurate centration. This we believe to be a function of the better centration mechanism of this machine-that is, the suction mask, which places control of centration into the operator's hands. The second reason, is that the stromal bed is much more difficult to mark with landmarks for ablation, as gentian violet cannot of course be applied to the interface. This is in contrast with high myopic PRK, where the optic zone is easily determined after marking with gentian violet. The third factor is that very much higher corrections are attempted with LASIK, so the procedural duration is longer (therefore giving more time in which decentration can occur), and these very 
high myopic LASIK patients have poor (unaided) visual acuity - which makes visualisation of the fixation target difficult. In their series, Bas and Onnis ${ }^{13}$ found three cases of decentration (greater than $1.0 \mathrm{~mm}$ ), while Fiander and Tayfour ${ }^{14}$ found five cases of 'mild' decentration associated with induced regular astigmatism (both used Summit lasers). Pallikaris and Siganos ${ }^{12}$ found that centration in their PRK and LASIK groups were comparable; their cases were all performed with an Aesculap Meditec device which would, for previously mentioned reasons, seem to improve centration.

Corneal problems occurred in 17 cases (35\%). Among these were cap stress lines, epithelial ingrowth, interface debris, and interface haze (see Table 5 for a complete list of corneal complications).

Cap stress lines occurred in two patients, but both showed no reduction in visual acuity. These stress lines are felt to be at the level of Bowman's membrane, and are probably due to undetectable intraoperative misalignment of the corneal cap on the stromal bed. Epithelial ingrowth and interface debris are really variations of the same problem-contamination of the interface. Epithelial cells from the conjunctiva or lid margins may be swept onto the interface by excessive irrigation, or excessive patient tearing. Epithelial ingrowth can be removed relatively easily, as was done in our retreatment cases. Interface debris may arise from the keratotomy incision itself, the instruments, or from the swabs used to clean the interface. We are currently using Merocel sponges (Merocel Corp, Mystic, USA), which seem to shed less debris than other varieties. We also use gentle aspiration on the interface to minimise sponging. Unfortunately, there is the risk of tearing the hinge if the flap is engaged, therefore a reflux facility is necessary on the aspiration unit. The problems arising from interface haze (nine cases), were examined subjectively - that is, only in terms of the presence or absence of glare and halo phenomenon. Of these nine cases, only one patient with grade 2 haze had visual problems (night driving difficulty). Unfortunately, contrast sensitivity testing was not examined in our series, nor has it been examined in any other reported LASIK series. This is an important quality control test of the technique, as other refractive procedures-for example, epikeratophakia and PRK, are associated with drastic reductions in contrast sensitivity.

Retreatment procedures for the treatment of undercorrection, central islands, or epithelial ingrowth combined with undercorrection (as was seen in two cases in this series) proved satisfactory and technically simple. Although predictability was good (see Table 1), two of the cases retreated lost 1 Snellen line, presumably due to undetectable interface abnormalities. The actual technique for performing a retreatment is relatively straightforward, as the flap has already been created during the original procedure; however, the critical point to bear in mind is that the residual corneal thickness will determine how much more cornea can be ablated. Part of the versatility of LASIK lies in the fact that, by relifting the flap, complications with the original procedure can be corrected at a second sitting. We feel that retreatment should be delayed till at least 9 months postoperatively when the refraction will be stable. In group $3 \mathrm{ML}$ patients it might be preferable to wait until 1 year, so that the full amount of regression can be determined.

In conclusion, LASIK is an exciting new technique which currently offers the surgeon a one step extraocular procedure for the treatment of high myopia. Its advantages are little/no postoperative pain and haze and a simple postoperative regime, which requires only a Cartella shield (for a few days), no pad, and a short 4 to 5 day course of postoperative antibiotics, topical steroids being unnecessary. LASIK is, however, no panacea. The disadvantages include the need for a fully functioning theatre suite and the purchase of an expensive microkeratome. The actual surgical procedure is technically difficult, and it should only be performed by an experienced ophthalmic surgeon. Furthermore, because of the creation of a flap, the risk of infection is theoretically greater, and because the intraocular pressure must be elevated so high $(65 \mathrm{~mm} \mathrm{Hg})$ during the keratotomy, there is, therefore, some concern about the possibility of inducing macular damage in these high myopes.

Corneal (extraocular) procedures, while attractive as regards safety, unfortunately lack the predictability of their alternatives (intraocular procedures such as clear lens exchange). There is still a long way to go with this technique, in particular improving the microkeratome, making it safer and more user friendly. More accurate nomograms need to be developed in order to improve the predictability of the procedure, and with the combined use of LASIK and multizone or multipass strategies some of the problems detailed above can be overcome. These steps will significantly advance this technique, and perhaps even allow it to compete with PRK as a treatment for low myopia. At our unit we are currently expanding the technique to include the treatment of hyperopia. This is an exciting new development in the field of refractive surgery.

1 Carson CA, Taylor HR. Excimer laser treatment for high and extreme myopia. Arch Ophthalmol 1995;113:431-6.

2 Sher NA, Barak M, Daya S. Excimer laser photorefractive keratectomy in high myopia:a multicenter study. Arch Ophthalmol 1992;110:935-43.

3 Ditzen K, Anschutz K, Schroeder E, Dausch B. Photorefractive keratectomy to treat low, medium and high myopia. f Cataract Refract Surg 1994;20:234-6.

4 Dausch D, Klein R, Schroeder E, Dausch B. Excimer laser photorefractive keratectomy with tapered transition zones for high myopia: a preliminary report of 6 cases. 7 Cataract Refract Surg 1993;19:590-4.

5 Heitzman J, Binder P, Kasser B, Nordon L. The correction of high myopia using excimer laser. Arch Ophthalmol 1993; 111:1627-34

6 Snibson C, Carson G, Aldred H, Taylor H. One year evaluation of photorefractive keratectomy for myopia and myopic astigmatism. Arch Ophthalmol 1995;113:994-1000.

7 Kim J, Woo S, Park C, Hahn T, Kim M. Myopic regression after photorefractive keratectomy. Ophthalmic Surg Lasers 1996;27:S435-9.

8 Pop M, Aras M. Multizone/multipass photorefractive keratectomy: six month results. F Cataract Refract Surg 995;21:633-43.

9 Pallikaris I, Papatzanaki M, Stahi E. Laser in situ keratomileusis. Lasers Surg Med 1990;10:463-8. 
10 Pallikaris I, Papatzanaki M, Siganos D. A corneal flap technique for laser in situ keratomileusis, human studies. Arch nique for laser in situ keratomile

11 Pallikaris I, Papatzanaki M, Georgiadis A, Frenschock O. A comparative study of neural regeneration following corneal wounds induced by argon fluoride excimer laser and mechanical methods. Lasers and Light in Ophthalmology 1990;3:89-95.

12 Pallikaris I, Siganos D. Excimer laser in situ keratomileusis and photorefractive keratectomy for the correction of high myopia. F Refract Corneal Surg 1994;10:498-510.

13 Bas A, Onnis R. Excimer laser in situ keratomileusis for myopia . F Refract Surg 1995;11:S229-33.

14 Fiander D, Tayfour F. Excimer laser in situ keratomileusis in one hundred and twenty-four myopic eyes. 7 Refract Surg 1995; 11:S234-8.

15 Gomes M. Laser in situ keratomileusis for myopia using manual dissection. F Refract Surg 1995;11:S239-43.

16 Kremer F, Dufek M. Excimer laser in situ keratomileusis. $\mathcal{F}$ Refract Surg 1995;11:S244-7.

17 Brint S, Ostrick O, Fisher C. Six month results of the multicenter phase 1 study of excimer laser myopic keratomileusis. 7 Cataract Refract Surg 1994;20:610-5.

18 Salah T, Waring GO, El Maghraby A, Moadel K, Grim S. Excimer laser in situ keratomileusis under a corneal flap for high myopia of two to twenty diopters. Am f Ophthalmol 1996;121:143-55.

19 Kremer I, Blumenthal M. Myopic keratomileusis in situ combined with Visx 20/20 photorefractive keratectomy. $f$ Cataract Refract Surg 1995;21:508-11.

$20 \mathrm{Kim} \mathrm{H}$, Jung $\mathrm{H}$. Laser assisted in situ keratomilcusis for high myopia. Ophthalmic Surg Lasers 1996;27:S508-11.

21 Martines E, John M. The Martines enhancement technique for correcting residual myopia following laser assisted in situ keratomileusis. Ophthalmic Surg Lasers 1996;27:S5126.

22 Marinho A, Pinto C, Pinto R, Vaz F, Neves M. Lasik for high myopia: one year experience. Ophthalmic Surg Lasers high myopia: one

23 Naylor E. Astigmatic difference in refractive errors. $\mathrm{Br} \mathcal{F}$ Ophthalmol 1968;52:422-5.

24 Buratto L, Ferrari M, Rama P. Excimer laser intrastromal keratomileusis. Am f Ophthalmol 1992;113:291-5.
25 Kreuger R, Talame J, McDonald M, Varnell R, Wagoner M, McDonnell P. Clinical analysis of excimer laser photorefractive keratectomy using multiple zone technique for severe myopia. Am f Ophthalmol 1994;117:456-61.

26 Epstein D, Fagerholm P, Nystrom H, Tengroth B. Twentyfour months follow-up of excimer laser PRK for myopia. Ophthalmology 1994;101:1558-64.

27 Carson C, Taylor H. Excimer laser treatment for high and extreme myopia. Arch Ophthalmol 1995;113:431-6.

28 McDonnell P, Garbus J, Hertzog L, Campos M. Photorefractive keratectomy for naturally occurring and postkeratoplasty astigmatism. Invest Ophthalmol Vis Sci 1992;33 (suppl):761.

29 Taylor H, Kelly P, Alpins N. Excimer laser correction of myopic astigmatism. I Cataract Refract Surg 1994;20 (suppl):243-51.

30 Taylor H, Guest C, Kelly P, Alpins N. Comparison of excimer laser treatment of astigmatism and myopia. Arch Ophthalmol 1993;111:1621-6.

31 Choli Y, Min H, Hyun P. Excimer laser photorefractive keratectomy for astigmatism. Korean 7 Ophthalmol 1993;7: $20-4$.

32 Spigelman A, Albert W, Cozean C, Johnson D, McDonnell $\mathrm{P}$, Pender $\mathrm{P}$, et al. Treatment of myopic astigmatism with $193 \mathrm{~nm}$ excimer laser utilising aperture elements. F Cataract Refract Surg 1994;20 (suppl):258-61.

33 Brancato R, Carones F, Trabucchi G, Scialdone A, Tavola A. The erodible mask in photorefractive keratectomy for myopia and astigmatism. Refract Corneal Surg 1993;9 (suppl): S125-30.

34 Snibson G, Carson C, Aldred G, Talor H. One year evaluation of excimer laser photorefractive keratectomy for myopia and myopic astigmatism. Arch Ophthalmol 1995;113: 994-1000.

35 Cavanagh T, Durrie D, Riedel S, Hunkeler J, Lesher M. Topographical analysis of the centration of excimer laser photorefractive keratectomy. F Cataract Refract Surg 1993; 19:610-5.

36 Mulhern M, Foley-Nolan A, O'Keefe M, Condon P. Topographical analysis of the centration of excimer laser in situ keratectomy in high myopia. $\mathcal{f}$ Cataract Refract Surg (in press). 